\title{
Gestor escolar inovador: educação da contemporaneidade
}

\author{
António Amorim
}

\section{Resumo}

Este artigo tem como problemática de análise a questão da gestão escolar, a situação atual e a perspectiva de inovação da gestão da escola básica brasileira. Tem como objetivo fazer uma reflexão em torno do perfil do atual gestor educacional, destacando o sexo, a idade, a formação, o trabalho e a remuneração por sua atuação e desempenho junto às milhares de escolas espalhadas por todo o território nacional. Em seguida, fazemos uma análise dos enfoques da administração, da gestão e da inovação dos processos gestores, definindo o papel do gestor em cada desses enfoques. Utilizamos a abordagem qualitativa de pesquisa, tendo o levantamento bibliográfico como parte instrumental do estudo. Isto porque a pesquisa bibliográfica tem como vantagem a permissão ao investigador de ter uma maior cobertura dos dados e das informações em questão, criando as facilidades para a comparação. Concluímos o trabalho reflexivo apontando as condições necessárias para que seja efetivado um perfil educacional do gestor inovador, aquele profissional que deve atuar na escola e garantir uma nova organização do ambiente pedagógico, das relações humanas, da efetivação de uma educação de qualidade, sendo bem remunerado e capacitado para o exercício de seu trabalho cotidiano.

Palavras-chave:

gestão escolar; inovação gestora; admnistração 


\title{
Innovative school manager: contemporary education
}

\begin{abstract}
This article has as problematic the issue analysis of school management, the current situation and the prospect of innovation of management of Brazilian elementary school. Aims to make a reflection around the current profile, educational Manager, highlighting the gender, age, education, work and remuneration for his role and performance along with thousands of schools throughout the national territory. Then we make an analysis of the approaches of administration, management and innovation of management processes, defining the role of the Manager in each of these approaches. We use qualitative research approach, having the bibliographic survey as part of the instrumental study. This is because the bibliographical research has the advantage of allowing the investigator to have greater coverage of data and information in question, creating facilities for the comparison. We conclude the reflective work the conditions for pointing that is effectively an innovative Manager's educational profile, that professional who must act in the school and ensure a new pedagogical environment, organization of human relationships, the establishment of a quality education, being skilled and well-paid for the exercise of their daily work.
\end{abstract}

Keywords: school management; managing innovation; management approach.

\section{Directeur de l'école innovatrice: enseignement contemporain}

Résumé: Cet article analyse la problématique de la gestion à l’école, sa situation actuelle, ainsi que la perspective d innovation de la gestion à l’école élémentairebrésilienne. Il soulève une réflexion sur le profil de l'actuel gestionnaire éducationnel, selon lesexe, l’âge, sa formation, son travail etsa rémunération par rapport à son rôle et à sa performance auprès des milliers d’écoles éparpillées sur le territoire national. L`article examine les approches de l’administration, de la gestion et de l`innovation de ces processus,tout en définissant le rôle du gestionnaire dans chacune de ces approches. Nous avons choisi l' approche qualitative de recherche, dont le relevé bibliographique s`inscrit dans le cadre de l’étude instrumentale. Ce relevé bibliographique a l`avantage de permettre au chercheur d `avoir un accès plus large aux données et auxinformations en question. Il crée aussi des conditions plus favorablesà leur comparaison. Pour conclure, cet article met en relief les conditions indispensables à établirle profil pédagogique d un gestionnaire innovateur, un professionnel qui doit assurerà l’école, une nouvelle organisation de l’environnement pédagogique et des relations humaines, la mise en place d une éducation de qualité - un professionnel bien qualifié et bien rémunéré pour bien exercer son métier.

Mots-clés: gestion de l'école; gestion de l'innovation; approche de gestion.

\section{Director de la escuela innovadora: la educación contemporánea}

Resumen: Este artículo tiene como problemático el tema Análisis de gestión escolar, la situación actual y la perspectiva de la innovación de la gestión de la escuela brasileña. Pretende hacer una reflexión alrededor del perfil actual, Gerente de educación, destacando el género, edad, educación, trabajo y remuneración por su papel y su actuación junto a miles de escuelas en todo el territorio nacional. Luego hacemos un análisis de los enfoques de la administración, gestión e innovación de procesos de gestión, definiendo el papel del administrador en cada uno de estos enfoques. Utilizamos el enfoque de investigación cualitativa, teniendo el estudio bibliográfico como parte del estudio instrumental. Esto es porque la investigación bibliográfica tiene la ventaja de permitir al investigador a tener una mayor cobertura de datos y la información en cuestión, crear instalaciones para la comparación de. Concluimos que el reflexivo trabaja las condiciones para señalar que es efectivamente el perfil educativo de un Manager innovadora, que profesional que debe actuar en la escuela y asegurar un nuevo ambiente pedagógico, organización de las relaciones humanas, el establecimiento de una educación de calidad, siendo calificados y bien remunerados para el ejercicio de su trabajo diario.

Palabras claves: gestión de la escuela; gestión de la innovación; enfoque de la gestión. 


\section{Introdução}

Neste artigo analisamos a questão do perfil do atual gestor da escola básica brasileira, considerando o sexo, a idade, a formação, o tempo de formação deste gestor e o grau de remuneração da profissão. Refletimos ainda sobre a experiência desse dirigente na condução das atividades pedagógicas, administrativas e financeiras das escolas, observando o desempenho deles na consolidação do projeto político pedagógico das escolas.

Precisamos conhecer a atuação dos dirigentes escolares para refletirmos sobre a qualidade do trabalho, a construção das relações humanas no cotidiano da instituição, bem como debater a questão dos enfoques da administração escolar, da gestão escolar conservadora e da gestão escolar inovadora, trazendo dados e informações que caracterizam o atual gestor escolar revelado pelo Censo Escolar da Educação Básica em 2013, para que seja projetado um possível perfil daquele gestor que poderíamos identifica-lo como sendo o gestor escolar inovador que irá atuar na construção de uma escola pública cidadã e de qualidade.

Para consolidar o estudo optamos pela abordagem qualitativa de pesquisa, colocando como instrumentalização a análise dos dados e das informações constantes do Censo Escolar de 2013, que foi divulgado pelo Instituto Nacional de Estudos e Pesquisas Educacionais - INEP.

Dessa forma, o estudo está estruturado por esta breve introdução, pela análise da situação atual do gestor escolar, em mais de 54 mil escolas, pelo país afora. Em seguida, trabalhamos os enfoques da administração escolar, da gestão escolar técnica e da gestão escolar inovadora, traçando o perfil do novo gestor que deverá atuar em nossas escolas e garantir o sucesso educacional e a formação cidadã para os nossos educandos.

Quem é o atual gestor da escola pública brasileira?

O perfil do atual dirigente da escola pública de educação básica brasileira pode ser revelado através da análise dos dados e das informações constantes do Censo Escolar de 2013. Estes dados foram coletados e projetados pelo INEP junto a mais de 54 mil escolas, em todo o país. São dados que projetam a condição formativa, idade, sexo e a atuação profissional de milhares de dirigentes escolares, colocando a importância que esses dirigentes têm na condução da atividade gestora.

É importante observar os dados referentes ao sexo dos nossos dirigentes escolares. Esses dados revelam que $84 \%$ são do sexo feminino e apenas $16 \%$ são do sexo masculino. Isto demonstra que as mulheres, em sua grande maioria, estão comandando a gestão da educação básica nas escolas públicas brasileiras. Esta informação é completada com a idade dos dirigentes: $10 \%$ têm até 29 anos 
de idade, $30 \%$ de 30 a 39 anos, $40 \%$ de 40 a 49 anos, $11 \%$ tem de 50 a 54 anos e $9 \%$ têm 55 anos ou mais. Ou seja, $70 \%$ dos dirigentes escolares tem idade que varia de 30 a 49 anos, demonstrando a importância da idade no exercício profissional dos gestores.

Em relação ao tempo de formação, 36\% dos dirigentes têm mais de 15 anos de formação; $28 \%$ estão com 8 a 14 anos; $28 \%$ têm de 3 a 7 anos e, apenas $8 \%$ dos dirigentes têm dois anos ou menos de formação. Ou seja, o dado mais importante é que $64 \%$ dos dirigentes têm mais de oito anos de formação, revelando que deveriam estar preparados, educacionalmente, com nível superior, para o exercício da profissão nas escolas.

0 perfil do gestor demonstra que, no geral: $41 \%$ dos dirigentes tem formação em Pedagogia; $36 \%$ em outras licenciaturas; $4 \%$ tem formação em Normal Superior; $6 \%$ formação de nível médio; $13 \%$ com formação superior em outros cursos que não são licenciaturas. Isto demonstra a importância formativa dos cursos de Pedagogia, que contribui de maneira significativa para a formação do gestor da escola básica brasileira.

É significativo também verificar que $51 \%$ dos dirigentes trabalham em educação há mais de 20 anos, 38\% tem entre 10 a 19 anos de exercício na educação, $11 \%$ dos dirigentes trabalham em educação até 10 anos. Este trabalho é destacado da seguinte maneira:

- a função de direção é exercida há mais de 10 anos por $21 \%$ dos dirigentes, $25 \%$ exercem esta atividade entre 5 a 10 anos, 30\% tem menos de 10 anos de profissão de direção;

- $19 \%$ dos dirigentes exercem a direção na mesma escola há menos de um ano, $14 \%$ têm de um a dois anos, $34 \%$ têm de dois a cinco anos, $22 \%$ tem de cinco a dez anos e $11 \%$ têm acima de dez anos de atuação como dirigente da mesma escola.

Outra informação que merece destaque, diz respeito à origem da instituição que realizou o curso superior: $59 \%$ fizeram curso em instituições privadas de ensino superior e $39 \%$ em instituições públicas. Desse total, $64 \%$ são universidades, $20 \%$ Faculdades isoladas e $11 \%$ Centros Universitários. Dos que realizaram curso superior em instituições públicas, à maioria pertence as universidade estaduais, em todo o Brasil.

Merece destaque ainda a modalidade de ensino cursada pelo dirigente, se presencial ou à distância. Neste sentido, $81 \%$ dos dirigentes responderam que realizaram o curso superior na modalidade presencial, $11 \%$ semipresencial e $8 \%$ em cursos à distância. Isto coloca a importância do ensino presencial atuando na formação dos dirigentes escolares.

Em relação à carga horária de trabalho na escola e como dirigente, $67 \%$ responderam que tem até quarenta horas semanais de exercício na escola, $26 \%$ 
tem mais de quarenta horas, $3 \%$ tem até vinte horas de trabalho e $4 \%$ até trinta horas de atividades semanais. Isto demonstra que, aproximadamente $70 \%$ dos dirigentes escolares atuam com quarenta horas semanais de trabalho, tendo o tempo necessário para desenvolver as atividades gestoras nas escolas públicas, podendo desempenhar com qualidade o seu tempo de trabalho.

E quanto ganha o gestor de nossas escolas, eles tem um salário adequado para exercer a sua função? Os dados do Censo Escolar de 2013 demonstraram com muita evidência que, considerando o salário bruto junto com os adicionais como dirigente escolar: $26 \%$ ganham de cinco até sete salários mínimos, $24 \%$ recebem de três e meio a cinco salários mínimos, $18 \%$ ganham de dois a três salários mínimos, $5 \%$ recebem de um a dois salários mínimos e $3 \%$ ganham menos de um salário mínimo como dirigente escolar.

Ou seja, notamos que juntando o salário bruto com os adicionais, $50 \%$ dos dirigentes escolares recebem de três e meio a sete salários mínimos por mês para exercer a sua atividade profissional. Este dado revela que, na moeda de hoje, $50 \%$ dos dirigentes escolares percebem um salário que varia de $\mathrm{R} \$ 2.758,00$ a RS 5.516,00, o que demonstra ser muito pouco para o exercício de uma profissão tão importante, em nosso sistema de ensino. Isto quer dizer que estes $50 \%$ dos dirigentes recebe de $\mathrm{R} \$ 91,93$ a $\mathrm{R} \$ 183,86$ por dia de trabalho nas escolas. Da mesma forma, podemos observar que o valor por hora de trabalho varia da seguinte forma: Da mesma forma, podemos observar que o valor por hora de trabalho varia da seguinte forma: de $R \$ 11,49$ a $R \$ 22,98$ por hora de trabalho.

A disparidade salarial chega a tal ponto que ainda existe dirigente, segundo os dados do Censo Escolar de 2013, num total de $3 \%$ dos 54 mil dirigentes entrevistados, que recebem menos de um salário mínimo para exercer a profissão de gestor escolar. Ou seja, mais de 1600 diretores recebem menos de $\mathrm{R} \$ 788,00$ para exercerem a função de dirigente escolar. Este é um fato muito grave, dado a condição das exigências do Plano Nacional de Educação e do pagamento do piso salarial do professor de educação básica defendido pelo Fundo Nacional de Desenvolvimento da Educação Básica e de Valorização do Magistério - FUNDEB.

Quando perguntado se o dirigente exercia outra atividade profissional para completar a sua renda familiar: $72 \%$ disseram que não, $21 \%$ falaram que sim e que essa atividade era desenvolvida na própria área de educação, $7 \%$ também exercem outra atividade profissional, sendo esta fora da área de educação.

É necessário demonstrar a nossa preocupação com o processo de escolha dos dirigentes de nossas escolas. Neste sentido, os dados revelam que a nossa perplexidade tem sentido, pois este processo tem demonstrado que $10 \%$ dos dirigentes são escolhidos através de seleção institucional, $21 \%$ através do processo de eleição, $14 \%$ através do processo conjugado de seleção e de eleição, 
$12 \%$ são escolhidos através de indicação técnica, $22 \%$ são ainda através de indicação de políticos, (o chamado "Ọl", quem indicou?), 21\% tiveram outras indicações. Isto quer dizer que $45 \%$ dos dirigentes são escolhidos por processos de seleção, de eleição ou de eleição/seleção ao mesmo tempo. Enquanto isto, $22 \%$ dos dirigentes ainda são escolhidos pelo processo de indicação política; considerando-se o total de 54 mil dirigentes entrevistados, $22 \%$ correspondem a 11.880 dirigentes que ainda são agraciados politicamente para exercer uma função que, muitas vezes, eles não têm o menor preparo institucional, numa clara demonstração da falta de critérios de qualidade na escolha desses dirigentes.

Os dados acima são corroborados pela indicação dos dirigentes que ao serem questionados sobre as condições internas para o exercício da direção, e se havia alguma interferência externa para o exercício da profissão: $37 \%$ disseram que existia interferência externa e $63 \%$ disseram que não. Trata-se de uma parcela significativa de nossos gestores escolares que denunciam a velha interferência externa na vida das escolas de educação básica, em todo o país. Isto representa um total de 19.980 dirigentes que denunciam a interferência externa nos assuntos da escola.

No andamento do estudo percebemos, ainda, que $95 \%$ dos dirigentes das escolas básicas que responderam o questionário do Censo Escolar de 2013, destacaram a existência de condições para o exercício do cargo, em cada escola, onde respondem pela gestão, tendo o apoio da comunidade para a realização deste trabalho. Apenas 5\% dos dirigentes acusaram a não existência de condições de trabalho e não tem o apoio da comunidade. É uma situação confortável para os dirigentes terem o apoio de parcela significativa da comunidade e condições institucionais pra o exercício da profissão. Na prática, não é de fato o que costumamos ver, pois segundo Amorim (2012) falta, muitas vezes, o essencial para que a escola pública garanta o seu funcionamento, trabalhe com qualidade e envolva nesta participação todos os segmentos que compõem o projeto de vida na escola. 
Em relação à participação da comunidade na gestão do Projeto Político Pedagógico da Escola, os gestores se manifestaram da seguinte forma: $42 \%$ consideraram que o Projeto foi construído pelos professores, pais, servidores, estudantes e os gestores da escola. Para $19 \%$ dos gestores, o Projeto foi consolidado por um grupo de professores, tendo a participação dos gestores da escola; $15 \%$ dos gestores afirmam que o modelo de projeto da escola é o mesmo encaminhado pela Secretaria de Educação. Em 4\% das escolas, os gestores declararam que não existe Projeto Político Pedagógico - PPP, em vigor. Ou seja, em mais de duas mil escolas não existe o Projeto político pedagógico em funcionamento. Esta é uma clara demonstração da falta de cumprimento da legislação educacional, que exige das escolas à construção do PPP. Para Veiga (2001), o PPP é um importante instrumento pedagógico a serviço da escola e da sociedade. Logo, é uma ferramenta que todos os gestores precisam conhecer para ofertar atividades integradas no ensino, na administração e no diálogo com a comunidade.

Finalmente, os dados do Censo Escolar de 2013 demonstraram também que $94 \%$ dos dirigentes consideram que existe a possibilidade "da troca de experiência" entre os gestores de outras escolas, apenas $6 \%$ responderam que esta prática não existia entre os gestores. Da mesma forma, 95\% dos dirigentes responderam que a comunidade oferece apoio sim às atividades da escola e $5 \%$ disseram que esta colaboração não existia.

Os enfoques de gestão no percurso histórico da escola

De acordo com Martins (1999) há dois enfoques no âmbito da administração e da gestão escolar: o primeiro diz respeito ao modelo de administração da escola de maneira burocrática e o segundo trata da gestão num enfoque diferenciado. Isto pode ser visualizado no quadro abaixo, onde demonstramos o enfoque de administração da escola, o de gestão da escola e a introdução do terceiro enfoque: o da gestão inovadora. 
Quadro n. 01 - Enfoque de administração escolar, enfoque de gestão escolar e de gestão escolar inovadora.

\begin{tabular}{|c|c|c|}
\hline $\begin{array}{c}\text { ENFOQUE } \\
\text { DE ADMINISTRAÇÃO }\end{array}$ & ENFOQUE DE GESTÃO & $\begin{array}{l}\text { ENFOOUE DE GESTÃO } \\
\text { INOVADORA* }\end{array}$ \\
\hline $\begin{array}{l}\text { Da ótica } \\
\text { fragmentada } \\
\text { para óptica } \\
\text { globalizadora. }\end{array}$ & $\begin{array}{l}\text { Cada um faz parte da } \\
\text { organização e do sistema } \\
\text { como um todo. }\end{array}$ & $\begin{array}{c}\text { Todos atuam de maneira coletiva, } \\
\text { consolidando a organização escolar } \\
\text { e o sistema geral, criando uma } \\
\text { cultural escolar. }\end{array}$ \\
\hline $\begin{array}{l}\text { Da limitação de } \\
\text { responsabilidade } \\
\text { para sua expansão. }\end{array}$ & $\begin{array}{l}\text { Redefinição de } \\
\text { responsabilidades e não } \\
\text { de funções. }\end{array}$ & $\begin{array}{c}\text { Aprimoramento da atuação de cada } \\
\text { ator social para engrandecer a } \\
\text { qualidade educacional do que vem } \\
\text { sendo realizado }\end{array}$ \\
\hline $\begin{array}{l}\text { De ação episódica } \\
\text { para o processo } \\
\text { contínuo. }\end{array}$ & $\begin{array}{l}\text { Cada evento, circunstância } \\
\text { e ato, são partes de um } \\
\text { conjunto de eventos, } \\
\text { circunstâncias e atos que } \\
\text { devem ser orientados para } \\
\text { resultados a curto, médio } \\
\text { e longo prazo. "Pense } \\
\text { grande e aja pequeno". } \\
\text { (Amir Klink). }\end{array}$ & $\begin{array}{l}\text { Uma visão de totalidade do } \\
\text { processo educacional, colocando } \\
\text { também a importância do que é } \\
\text { específicolocal e regional. }\end{array}$ \\
\hline $\begin{array}{l}\text { Da hierarquização } \\
\text { e burocracia para a } \\
\text { coordenação. }\end{array}$ & $\begin{array}{c}\text { Desenvolvimento e } \\
\text { aperfeiçoamento da } \\
\text { totalidade dos membros } \\
\text { do estabelecimento, } \\
\text { compreensão da } \\
\text { complexidade do trabalho } \\
\text { pedagógico e percepção } \\
\text { da importância da } \\
\text { contribuição individual e } \\
\text { da organização coletiva. }\end{array}$ & $\begin{array}{c}\text { Desenvolvimento de competências } \\
\text { e de habilidades contemporâneas, } \\
\text { de modo que todos os membros da } \\
\text { escola entendam a complexidade } \\
\text { do que é construído e difundido } \\
\text { pela escola, para o crescimento da } \\
\text { comunidade interna e externa à } \\
\text { escola. }\end{array}$ \\
\hline $\begin{array}{l}\text { Da ação individual } \\
\text { para a coletiva. }\end{array}$ & $\begin{array}{l}\text { Desenvolvimento e } \\
\text { aperfeiçoamento de ação } \\
\text { coletiva, de espírito de } \\
\text { equipe. }\end{array}$ & $\begin{array}{c}\text { Desenvolver o trabalho em equipe, } \\
\text { aperfeiçoar o trabalho colaborativo } \\
\text { para criar um ambiente inovador } \\
\text { dentro da escola, aumentando as } \\
\text { possibilidades educativas e sociais } \\
\text { de todos. }\end{array}$ \\
\hline
\end{tabular}

Quadro elaborado por Martins (1999) e complementado pelo pesquisador*.

O Enfoque de Administração Escolar considera que a escola está dividida precisando unir burocraticamente as suas partes, passando de uma ação que ocorre esporadicamente para um processo contínuo, com hierarquização das ações, tendo a participação individual como chave do processo, que irá progressivamente envolvendo os demais participantes da escola neste processo de mudança. 
Já o Enfoque de Gestão vê o todo da instituição, com todos fazendo parte do mesmo processo, com redefinição das responsabilidades, ações ocorrem de maneira planejada, sendo que as circunstâncias fazem parte de uma situação que é global, complexa e que exige a participação coletiva para buscar as soluções.

O Enfoque da Gestão Inovadora exige que todos participem do processo, contribuam para a consolidação de mudanças significativas no ambiente da escola e no sistema de ensino como um todo, para criar uma cultura escolar e educacional que traga uma visão de totalidade da vida escolar, contribuindo para o desenvolvimento de habilidades e de competências inovadoras, que irão fortalecer o trabalho do gestor, tendo a participação de equipes colaborativas e inovadoras.

Com esses três enfoques, observamos que o processo de inovação educacional ou da gestão escolar tem várias facetas institucionais. Exige uma construção coletiva, uma definição de sua abrangência e tem caráter de diversidade, de alcance multidimensional, pois apresenta um conjunto de facetas que exige o uso da tecnologia da informação e da comunicação. Trata-se de considerar os três enfoques amparados num processo de planejamento, de consolidação de estratégias institucionais, que apresentam uma veia ideológica e politica. Cada um tem a um tipo de ideologia e de um processo político, e isto ocorre de acordo com os interesses que os grupos institucionalizados defendem, de acordo com o modelo de escola e de gestão que precisam ser trabalhados. Os dois enfoques de gestão e de gestão inovadora revelam um processo que faz parte da mudança e da transformação daquilo que está em curso, com a sua alteração organizacional. 0 enfoque de administração deseja mudança, sem muita alteração no processo, pois este enfoque prioriza o produto final em detrimento das questões processuais.

As escolas têm uma função secular de transmissoras dos saberes produzidos socialmente pelas comunidades onde elas atuam. Isto ocorre de geração para geração, em cada etapa histórica, colocando as instituições de ensino como sendo uma organização marcante na vida das pessoas. Essas instituições procuram mudar em seu ambiente pedagógico e institucional para criar uma nova cultura que seja individual e coletivamente referenciada, com práticas individuais e sociais que se aproximam e se contradizem ao mesmo tempo, servindo de espaço inovador. É um movimento dialético que a sociedade realiza através das instituições de ensino para aproximar o passado ao presente e o presente abre espaços dinâmicos para aproximar o futuro, antecipando e revelando experiências e saberes socioeducacionais, socioemocionais e sociopessoais que aprofundam e engrandecem a perspectiva histórica da educação e da escola, o dever ser da educação. 
Entendemos que a escola, em qualquer enfoque que atua, tem o desejo de construir novos saberes. Por isso, o saber ou saberes escolares devem ser compreendidos, aqui, como sendo um conjunto complexo de representações formais e informais, que estão sempre em processo e que advém da práxis humana, da diversidade, da ação interdisciplinar e multidisciplinar das atividades exercidas pelos alunos, professores, comunidade interna e externa à escola, e que, segundo Chevallard (1991) tem uma epistemologia própria, sendo esta social, cultural e educacionalmente referenciada.

Os enfoques de gestão e de gestão inovadora têm uma dinâmica de construção permanente, ou seja, são dialeticamente processuais e contribuem para a construção de uma educação escolar transformadora. Então, a gestão dos saberes na escola precisa acompanhar o processo de inovação permanente, para colocar as instituições de ensino sempre atualizadas, referenciadas, em sintonia com o seu tempo, atuando muito além do processo de assimilação e de reprodução, para se tronarem, também investigativas e epistemologicamente envolvidas na busca pelos saberes inovadores.

Já percebermos que a gestão escolar é, por natureza, um processo complexo que exige a integração de diferentes saberes e de modelos científicos para definir a sua concepção e projetar um lugar da gestão no cenário educacional.

Isto evidencia a importância que tem a gestão escolar, no tempo presente, para atuar de maneira dinâmica no processo gestor das instituições de ensino e incorporar uma visão contemporânea de escola, com novas metodologias e novos conhecimentos que contribuam para a melhoria qualitativa da vida pedagógica e social, para a formação de uma educação escolar que considere a relevância que tem os saberes dos alunos e dos professores, os saberes populares e os saberes científicos.

Historicamente, o papel da gestão escolar inovadora vem sendo ressaltada por autores consagrados como Libâneo (2004), quando trata da questão da organização e da gestão da escola e defende a necessidade de maior participação da comunidade escolar nos processos gestores. Da mesma forma, Heloisa Luck (2008) chama a nossa atenção para as dimensões da gestão escolar e para a formação das competências nestas dimensões. Saviani (1997) fala da relevância de se ter uma escola democrática e participativa. Outro educador progressista é Vitor Paro (2007), que nos alerta para a necessidade de uma melhor compreensão dos processos administrativos no interior das instituições de ensino.

De fato, os educadores e as instituições de ensino têm um importante compromisso com o desenvolvimento da educação e do funcionamento pleno das escolas. É através das instituições de ensino que a sociedade efetiva a sua 
leitura do mundo e cria as condições efetivas para aprimorar a transformação social e produtiva.

A construção de um novo perfil para o gestor inovador exige mudança profunda na forma de ver e de fazer a educação nas instituições de ensino, sendo necessário ainda considerar o ideário traçado por Veiga (2001): romper de maneira definitiva com as estruturas mentais e organizacionais fragmentadas existentes na educação e nos sistemas de ensino; definir e consolidar o vir a ser da escola baseado em princípios e diretrizes contextualizadas; criar utopias pedagógicas a partir da vontade política da comunidade escolar rompendo com o individualismo e estabelecendo a parceria e o diálogo franco; fortalecer o processo de diagnóstico da escola, considerando a avaliação como sendo necessária, para solucionar os problemas enfrentados individual e coletivamente.

Finalmente, há que considerar o planejamento participativo como sendo uma ferramenta necessária para gerar compromissos e a realização de metas importantes para a escola, garantindo a essência da instituição: ser o lugar onde os saberes científicos e os saberes populares devem ter uma existência democrática, valorizando-se a formação de uma cultura integradora para os membros da comunidade escolar.

Qual deve ser o perfil do gestor escolar para atuar na escola pública de qualidade e garantir a inovação da gestão?

Depois de ser analisada a questão da inovação educacional e escolar, de discutir o papel da educação e da escola na contemporaneidade, de establecer as principais dimensões gestoras innovadoras da gestão da escola, de entender a realidade da gestão nas escolas brasileiras, de estudar a questão dos enfoques de gestão, é chegado o momento de pensarmos num perfil transformador para o gestor escolar que deseja ser innovador.

Por isso, diante de toda problemática inovadora e gestora que vivem as nossas instituições de ensino, entendemos ser necessário buscar um perfil atualizado, que indique o caminho para que o gestor possa buscar a inovação de sua gestão. 0 gestor inovador deve incorporar em seu trabalho diário um perfil de ser a pessoa do diálogo dentro da escola, retirando aquela capa de autoridade imutável, daquele administrador que determina sempre o que fazer e do como fazer. Ele precisa mudar o seu comportamento e trabalhar de maneira colaborativa, grupal, fazendo com que as pessoas percebam o que deve ser feito e a qualidade necessária que cada etapa do processo exige.

Esse perfil é iniciado nas considerações de Rowe (2002), quando chama a nossaatenção para o fato do gestor exercer uma liderança visionária, sendo neste sentido, verdadeiros líderes estratégicos. O gestor visionário é sempre 
aquele que percebe as partes e o todo institucional, planeja o seu trabalho e envolve as pessoas neste processo. 0 gestor inovador será sempre aquele que atuará considerando como referencia, para o seu desempenho institucional, a tela formada pelas onze dimensões gestoras que foram analisadas ao longo deste trabalho. Este gestor inovador precisa exercer uma competência social e educacional em suas atividades, tendo ao longo do tempo de sua profissão o perfil que, a seguir, será caracterizado.

- É um gestor inovador porque defende a educação e a escola como sendo o lugar estratégico para desenvolver saberes diversificados, cientificamente e socialmente referenciados e necessários para o desenvolvimento humano.

- Acredita no trabalho em equipe, sendo por natureza uma pessoa democrática, que valoriza os processos autônomos e desperta todos para realizar sempre o melhor institucionalmente.

- É um gestor flexível, proativo, um líder, que confía plenamente na capacidade criativa de alunos, professores, pessoal técnico e administrativo da escola e membros da comunidade externa.

- Trata-se de um gestor que está sempre motivado, trabalha de maneira planejada, que passa confiança e desperta todos para agir e fazer o melhor pela escola.

- Cria canais de integração da escola com a sociedade e com os poderes públicos, de modoa ampliar os espaços de realização educacional e cultural, fazendo do ambiente escolar um lugar de diálogo, de escuta, de comunicação permanente para promover a inovação das relações pessoais, profissionais e emocionais.

- Estimula a formação de grupos de reflexão, de avaliação, de autoavaliação, para corrigir e fortalecer a vida pedagógica, social, cultural, administrativa e financeira da instituição.

- Considera-se um ser aprendente, que atua numa instituição aprendente, construindo novas possibilidades teóricas e metodológicas para fazer frente as demandas que são oriundas da complexidade da ação escolar.

- Fortalece o trabalho pedagógico dos professores e dos alunos, em sala de aula, reconhecendo o crescimento individual e coletivo de todos.

- Tem o controle efetivo das necessidades materiais, humanas e financeiras da escola, atuando de maneira prospectiva para não deixar que haja descontinuidade naquilo que foi planejado e que está sendo executado.

- É um profissional inovador das aprendizagens, da construção dos projetos da escola, do funcionamento dos conselhos, atuando para a realização do planejamento de curto, de médio e de longo prazos.

- Atua na formação contínua dos quadros de pessoal da escola, ampliando os espaços formativos de professores, de colaboradores da gestão e demais servidores da instituição. 
Além de tudo isso, entendemos que o gestor inovador precisa ter a consciência de que a gestão escolar é uma ação política, que exige uma visão ampliada da escola e da sociedade para fazer frente as possíveis dificuldades econômicas e sociais que precisam de parcerias externas para serem equacionadas.

Neste sentido, Dourado (2000) explica aos dirigentes escolares que o processo educacional não é uma ação neutra, que está fora de um contexto social e económico. Neste sentido, é preciso ver a escola como sendo um lugar social e cultural, uma parte do contexto social, que tem um compromisso histórico com a maioria da população.

De uma maneira comparativa é possível ampliar este perfil do gestor escolar inovador, tomando como base o quadro idealizado por Souza (2006), quando analisa as atribuições de um diretor de escola e de um gestor escolar, destacando quais são os perfis de ambos na condução da vida institucional. Em seguida, por iniciativa nossa, o quadro é ampliado com o perfil que deve ter um gestor escolar inovador.

Destacamos nesse perfil que o ambiente da escola é praxeológico. Ou seja, é um ambiente científico, cultural, social, emocional, pedagógico e contraditório, complexo e diversificado. Por isso mesmo, trata-se de um lugar da complexidade onde todas as atividades desenvolvidas e os atores sociais que atuam neste ambiente contribuem para o sentido de heterogeneidade educacional e escolar, ampliado desta forma o clima de perplexidade diante do desconhecido, do inovador e do diversificado.

Diante de tudo isso, é importante que o gestor atue considerando a gestão inovadora como sendo a sua bandeira de trabalho dentro das instituições de ensino. Com isto fica garantido o estabelecimento de relações humanas promissoras que irão propiciar à consolidação da gestão democrática, da inovação educacional, da qualidade dos processos e da autonomia das pessoas, observando-se a efetivação da avaliação do projeto político pedagógico, indo ao encontro da qualidade, da participação e da integração das decisões internas na escola.

\section{Conclusão}

Durante o processo de reflexão proporcionado por este trabalho, podemos perceber a importância que tem a inovação educacional para a escola, para os sistemas de ensino e para o trabalho do gestor escolar. Vimos que é necessário melhorar o perfil deste gestor e criar as condições essenciais para envolver a reflexão em torno da atividade de ensino para buscar a inovação da vida pedagógica, na sala de aula, com a incorporação das tecnologias criativas ao processo de gestão do ambiente escolar.

Constatamos também que a gestão escolar precisar enfrentar os desafíos que são colocados no intinerário do gestor, para observa a existência de muitas 
dificuldades para operar mudanças educacionais no meio da sociedade, sendo que este ciclo se repete junto às nossas escolas. Observamos ainda que é papel da escola passar por este processo inovador, tornando-se referência educacional, social e cultural para milhões de crianças que vão, todos os dias, as escolas brasileiras.

Por isso, entendemos que na construção do novo perfil do gestor contemporâneo seja preciso transformar as instituições de ensino, colocando-as como sendo laboratório de experimentos pedagógicos, de construção das subjetividades sociais, para que elas possam funcionar como sendo verdadeiros laboratórios culturais da inovação educacional, tendo o gestor como sendo o articulador desta inovação, sendo necessário trabalhar, de forma coletiva, de maneira interdisciplinar com o professor, o aluno, o gestor e a comunidade de pais de alunos, para garantir o desenvolvimento de projetos de investigação que propiciem o despertar de novas metodologias de ensino, de renovação dos conteúdos trabalhados, de recursos didáticos inovadores e de tecnologias contemporâneas que auxiliem o educando na construção de novos saberes educacionais.

Assim, concluimos também ser atribuição do gestor escolar participar de todos esses processos, reconstruindo os espaços escolares para tornar essa instituição de ensino mais dinâmica, um organismo vivo de criatividade, de investigação, de valorização da diversidade. 0 gestor precisa entender que a escola é o lugar de realização das atividades contraditórias, um espaço pedagógico promissor para efetivar mudanças e buscar a inovação do conhecimento, produzindo saberes significativos para a sua comunidade.

A criação desses novos saberes deve propiciar a implantação de uma atmosfera participativa, que promova a vida democrática daqueles que fazem parte do ambiente inovador: alunos, professores, gestores, servidores técnico-administrativos e país de alunos. Todos devem agir de maneira coletiva para fortalecer a unidade em torno daquelo que se deseja mudar, fazendo da escola um lugar de decisão, de reflexão, de pesquisa e de ação inovadora.

Finalmente, diante disso, podemos afirmar que a gestão inovadora passará a ser sinônimo de participação, de compromisso, de mudança radical no comportamento dos gestores e das diferentes equipes da que atuam dentro e fora da instituição. Isso irá promover uma atmosfera inovadora, fazendo com que alunos e professores criem uma atitude pedagógica, deem um novo sentido para a questão do trabalho em equipe e envolva a comunidade na renovação dos diferentes projetos vivenciados no contexto escolar. 


\section{Referências Bibliográficas}

Abramovay, M. (Coord.). (2003). Escolas inovadoras: experiências bem-sucedidas em escolas públicas. Brasília: UNESCO.

Almeida, M.; Rubim, L. (2004). O papel do gestor escolar na incorporação das TIC na escola: experiências em construção e redes colaborativas de aprendizagem. São Paulo: PUC-SP.

Alves, G. L. (2006). A Produção da escola pública contemporânea. (4a ed). Autores Associados. Campinas, SP: Histedbr.

Amorim, A. (2007). Escola - uma instituição social complexa e plural. São Paulo: Editora Viena.

Amorim A. (2012). Políticas públicas em educação, tecnologia e gestão do trabalho docente. Salvador: EDUNEB.

Bauman, Z. (2006). Vida Líquida. Rio de Janeiro: Jorge Zahar Editor.

Brasília. (2013). Ministério da Educação. Censo Escolar.

Chevallard, Y. 1991). La transposición didáctica. Del saber sabio al saber enseñado. Buenos Aires: Aique Grupo Editor.

Cordiolli, M. (2003). Currículo, cultura escolar e gestão do trabalho pedagógico. Curitiba: A Casa de Asterion.

Dermeval, S. (1997). Gestão escolar numa perspectiva democrática. Piracicaba/SP: Editora UNIMEP.

Dourado, L. F. (2000). A escolha de dirigentes escolares: políticas e gestão da educação no Brasil. In Naura S. Carapeto Ferreira (Orgs.). Gestão democrática da educação: atuais tendências, novos desafios. (pp. 77-95). São Paulo: Cortez.

Dourado, L. F. et al. (2007). A qualidade da educação: conceitos e definições. Brasília: MEC.

Freire, P. (2004). Pedagogia da Autonomia: saberes necessários à prática educativa. (30ª ed.) São Paulo: Paz e Terra.

Gil, A. C. (2002). Como elaborar projetos de pesquisa. ( $4^{\mathrm{a}}$ ed). São Paulo: Atlas.

Libâneo, J. C. (2001). Buscando a qualidade social do ensino. In Libâneo, J. C. Organização e Gestão da Escola - Teoria e Prática. (pp. 53-60). Goiânia: Editora Alternativa.

Libâneo, J. C. (2004). Organização e gestão escolar: teoria e prática. Goiânia: Ed. Alternativa.

Luck, H. (2013). Perspectivas da gestão escolar e implicações quanto à formação de seus gestores. Em Aberto, 72 , 11-34.

Luck, Heloísa. (2008). Liderança em gestão escolar. Petrópolis, RJ: Editora Vozes.

Martins, J. P. (1999). Administração escolar. (2 ${ }^{\mathrm{a}}$ ed). São Paulo: Atlas.

Morin, E. (2006). Os sete saberes da educação do futuro. São Paulo: Cortez.

Paro, V. H. (2007). Gestão escolar, democracia e qualidade do ensino. São Paulo: Ática.

Rowe, W. G. (2002). Liderança estratégica e criação de valor. RAE - Revista de Administração de Empresas, 1 (XLII), 7-19. 
Saviani, D. (1997). A nova Lei da educação: trajetória, limites e perspectivas. (5ª ed). Campinas, SP: Autores associados.

Saviani, D. (2002). Escola e democracia. (35ª ed.).Campinas: Editora Autores Associados.

Souza, Â. R, de. (2006). O perfil da gestão escolar no Brasil. Tese de Doutorado (Educação: História, Política, Sociedade). São Paulo: PUC-SP.

Veiga, P. A. (org.) (2001). Projeto Político Pedagógico: uma construção possível. (16 a ed). São Paulo: Cortez.

\section{António Amorim}

Professor Titular Pleno da Universidade do Estado da Bahia. Doutor em Psicologia pela Universidade de Barcelona - Espanha. Membro da Academia Baiana de Educação antonioamorim52@gmail.com

\section{Correspondência}

António Amorim

Rua Alameda dos Flamboyants, n. 110, Ed. Mansão Modesto Cerqueira,

Ap. 1601. Caminho das Árvores, Salvador - Bahia CEP 41.820.410

Tel. 71-99984-8574

Data de submissão: Setembro 2016

Data de avaliação: Dezembro 2016

Data de Publicação: 2017 